\title{
Métodos de recuperação de pastagens de Brachiaria decumbens Stapf. no Agreste Pernambucano ${ }^{1}$
}

\author{
Daniel Fernando Ydoyaga ${ }^{2}$, Mário de Andrade Lira ${ }^{3^{*}}$, Mércia Virginia Ferreira dos Santos ${ }^{*}$, \\ José Carlos Batista Dubeux Júnior ${ }^{4}$, Maria da Conceição Silva ${ }^{2}$, Venézio Felipe dos Santos ${ }^{3}$, \\ Antônio de Pádua Maranhão Fernandes ${ }^{3}$
}

\author{
${ }_{1}$ Parte da dissertação apresentada à UFRPE pelo primeiro autor, trabalho financiado pelo BNB e realizado pelo Acordo IPA/UFRPE. \\ ${ }^{2}$ Doutorando em Zootecnia - UFRPE. \\ 3 IPA. \\ ${ }^{4}$ Departamento de Zootecnia - UFRPE. \\ * Bolsista do CNPq.
}

RESUMO - Este trabalho foi realizado com o objetivo de identificar metodologias que viabilizem a recuperação de pastagens degradadas de Brachiaria decumbens Stapf. no Agreste de Pernambuco. O delineamento experimental utilizado foi em blocos ao acaso com confundimento. Os tratamentos experimentais foram constituídos de quatro manejos de recuperação (diferimento, diferimento + gradagem, diferimento + gradagem + milho e diferimento + plantio direto do milho), duas doses de nitrogênio $(0$ e $100 \mathrm{~kg} / \mathrm{ha}$ de $\mathrm{N})$, duas doses de fósforo $\left(0\right.$ e $100 \mathrm{~kg} / \mathrm{ha}$ de $\left.\mathrm{P}_{2} \mathrm{O}_{5}\right)$, perfazendo 16 tratamentos, com três repetições. $\mathrm{O}$ corte foi realizado aos 138 dias do início do experimento. Houve interação entre as adubações utilizadas, evidenciando aumento na disponibilidade de matéria seca para as adição conjunta de $100 \mathrm{~kg} / \mathrm{ha}$ de $\mathrm{N}$ e $100 \mathrm{~kg} / \mathrm{ha}$ de $\mathrm{P}_{2} \mathrm{O}_{5}$. A disponibilidade de MS total foi superior nos métodos diferimento e diferimento + plantio direto, quando comparados aos tratamentos com gradagem. Aos 138 dias, houve ainda aumento na porcentagem de solo descoberto nos métodos com uso de grade, verificando-se o contrário nos tratamentos sem gradagem. A gradagem não se mostrou uma prática agronômica viável para a recuperação de pastagens degradadas em solos arenosos do Agreste Pernambucano, enquanto o diferimento da pastagem por 138 dias no período chuvoso propiciou a recuperação, principalmente quando associado à adubação nitrogenada e fosfatada. A recuperação da pastagem de Brachiaria decumbens Stapf. é expressivamente incrementada com a aplicação de adubos nitrogenado e fosfatado pela redução de outras espécies.

Palavras-chave: adubação fosfatada, adubação nitrogenada, gradagem, plantio direto

\section{Recovery methods of Brachiaria decumbens Stapf. pastures in the Agreste region of Pernambuco State}

\begin{abstract}
In order to identify methods of recuperation of degraded pastures in the Agreste of Pernambuco, an experiment was conducted in the Fazenda Riacho do Papaguaio, municipial district of São João. It was used a split-plot feature within a confounded randomized block design. The experimental treatments were four recovery managements (deferment, deferment + harrowing, deferment + harrowing + corn as a companion crop, deferment + corn as a companion crop), two levels of nitrogen $(0$ and $100 \mathrm{~kg} / \mathrm{ha}$ of $\mathrm{N})$, two levels of phosphorus ( 0 and $100 \mathrm{~kg} / \mathrm{ha}$ of $\left.\mathrm{P}_{2} \mathrm{O}_{5}\right)$, totalizing 16 experimental treatments with three replications. The harvesting evaluation was taken after 138 days from implementation of the experimental treatments. A significant $\mathrm{N}$ and $\mathrm{P}_{2} \mathrm{O}_{5}$ interaction was observed with marked increase in forage dry matter mass corresponding to the combination of $100 \mathrm{~kg} / \mathrm{ha}$ of $\mathrm{N}$ and $\mathrm{P}_{2} \mathrm{O}_{5}$. The deferment and deferment + corn treatments resulted in higher forage mass yield as compared to the harrowing ones. After 138 days of growth, there was an increase in the percentage of uncovered soil with plow use, while the opposite was true without the use of a plow. Plowing did not demonstrate agronomic viability as a degraded pasture recuperation practice. Allowing the pasture to rest for 138 days during the rainy season promoted its recuperation, primarily with the combined application of nitrogen and phosphate fertilizers. The recovery of nitrogen and phosphate fertilized Brachiaria decumbens Stapf. was associated with decrease of other species.
\end{abstract}

Key Words: P fertilization, $\mathrm{N}$ fertilization, plow, no-tillage

\section{Introdução}

O cultivo de forrageiras exóticas em detrimento das nativas é uma prática comum na pecuária brasileira e até mesmo compreensível pela sua superioridade produtiva.
Esse elevado potencial produtivo estimula os produtores à utilização de altas taxas de lotação nas pastagens, desrespeitando, muitas vezes, os efeitos sazonais de clima, principalmente em regiões semi-áridas como parte do Nordeste do Brasil. 
O Nordeste brasileiro ocupa aproximadamente $1.646 .500 \mathrm{~km}^{2}$, o que corresponde a $19,9 \%$ do território nacional (Araújo Filho \& Araújo, 2002), sendo formado, em grande parte, por regiões semi-áridas (Sá et al., 2004).

As pastagens implantadas no semi-árido de Pernambuco têm apresentado acentuado declínio na produtividade, principalmente de capim-pangola (Digitaria decumbens Stapf.) no Agreste e de capim-buffel (Cenchrus ciliaris L.) no Sertão (Rocha, 1985).

O esgotamento da fertilidade do solo, as alterações em suas propriedades físicas e o manejo inadequado têm ocasionado a degradação das pastagens cultivadas (Haddad \& Alves, 2002). Um dos exemplos de manejo inadequado que podem contribuir para o processo de degradação das pastagens é a adoção de mesma taxa de lotação animal durante todo o ano, fato comum no Nordeste brasileiro (Silva et al., 2004).

Segundo Macedo (1999), a percepção antecipada das etapas do processo de degradação e a utilização de indicadores são elementos importantes para evitar situações de quebra da sustentabilidade da produção. Na recuperação de pastagens degradadas, podem ser utilizados métodos diretos, como os mecânicos e químicos, ou indiretos, como culturas de grãos e pastagens anuais, que devem ser adequados a cada sistema de produção, visando maximizar as inter-relações biológicas, econômicas e sociais.

Silva et al. (2004), avaliando a degradação de pastagem Brachiaria humidicola em solo com 1 ppm de fósforo, observaram recuperação da pastagem apenas com a adubação fosfatada associada a um período de diferimento.

Este trabalho foi realizado com o objetivo de avaliar diferentes métodos de recuperação em pastagem degradada de Brachiaria decumbens Stapf. no Agreste de Pernambuco, bem como o efeito da adubação fosfatada e nitrogenada.

\section{Material e Métodos}

O experimento foi realizado na fazenda Riacho do Papagaio, em São João-PE, na micro-região do Agreste meridional do estado de Pernambuco, com coordenadas geográficas $8^{\circ} 52^{\prime} 30^{\prime \prime}$ 'de latitude sul, $36^{\circ} 22^{\prime} 00^{\prime \prime}$ ' de longitude oeste e altitude de 705. O clima predominante na região é o $\mathrm{AS}$ ', que equivale a um clima quente e úmido, conforme classificação de Köeppen (Fundação de Informações para o Desenvolvimento de Pernambuco, 1982).

A área experimental era formada por uma vegetação típica do Agreste, a qual foi retirada por volta de 1950, quando teve início o processo produtivo no referido local. Durante os primeiros 30 anos, prevaleceu a monocultura do algodão, cujo cultivo era realizado pelo sistema convencional, sem rotação de cultura e adubação para a reposição dos nutrientes ao solo. Posteriormente, com o declínio da produção do algodão a níveis antieconômicos, procedeu-se à transformação da área em pastagens de Brachiaria decumbens Stapf.

Durante o período experimental(20/05/2000 a 13/01/2001), a precipitação pluvial total foi de $540,6 \mathrm{~mm}$, com distribuição irregular de chuvas, com maior ocorrência no mês de junho (179,5 mm) e ausência nos meses de outubro e novembro.

Visando caracterizar a fertilidade original do solo, foram colhidas amostras de solo a $0-20 \mathrm{~cm}$ de profundidade, em três áreas próximas ao local do experimento, mantidas atualmente como reserva florestal. A análise da amostra composta revelou os seguintes valores: $\mathrm{pH}\left(\mathrm{H}_{2} \mathrm{O}\right)=5,5$; $\mathrm{P}=8,3 \mathrm{mg} / \mathrm{dm}^{3} ; \mathrm{K}^{+}=0,24 \mathrm{cmol}_{\mathrm{c}} / \mathrm{dm}^{3} ; \mathrm{Ca}^{++}=1,56 \mathrm{cmol}_{\mathrm{c}} / \mathrm{dm}^{3}$; $\mathrm{Mg}^{++}=0,98 \mathrm{cmol}_{\mathrm{c}} / \mathrm{dm}^{3} ; \mathrm{Na}^{+}=0,03 \mathrm{cmol}_{\mathrm{c}} / \mathrm{dm}^{3} ; \mathrm{Al}^{+++}=$ $0,16 \mathrm{cmol}_{\mathrm{c}} / \mathrm{dm}^{3} ; \mathrm{S}=3,46 \mathrm{cmol}_{\mathrm{c}} / \mathrm{dm}^{3} ; \mathrm{CTC}=9,1 \mathrm{cmol}_{\mathrm{c}} / \mathrm{dm}^{3}$; $\mathrm{v}=43 \%$ e $\mathrm{m}=19,3 \%$, indicando que o solo possuía originariamente fertilidade média.

$\mathrm{Na}$ área experimental, as amostras de solo foram retiradas nas profundidades de 0 a $20 \mathrm{~cm}$ e de 20 a $40 \mathrm{~cm}$ (Tabelas 1 e 2). Os valores encontrados para os macronutrientes na camada arável do solo foram baixos, entretanto, a composição química e física foi pouco influenciada pela profundidade. A comparação dos dados da Tabela 2 com os obtidos nas áreas preservadas evidencia o declínio na fertilidade do solo atribuído à exploração.

Desse modo, o solo da área experimental é um Regossolo com fertilidade original média, provavelmente empobrecido pela exploração sem reposição de nutrientes.

O delineamento experimental utilizado foi o de blocos ao acaso, com confundimento parcial da interação tripla, e os tratamentos consistiram de um arranjo fatorial $4 \times 2 \times 2$, com quatro métodos de recuperação da pastagem (diferimento, diferimento + gradagem, diferimento + gradagem + milho e diferimento + plantio direto do milho),

Tabela 1 - Analise química de amostras de solo da área experimental, São João-PE, nas profundidades de 0 a 20 e de 20 a $40 \mathrm{~cm}$ Table 1 - Chemical analysis of soil sample, at $0-20$ and $20-40 \mathrm{~cm}$ deep from experimental area, São João-PE

\begin{tabular}{|c|c|c|c|c|c|c|c|c|c|c|c|c|}
\hline $\begin{array}{l}\text { Camada } \\
\text { Stratum }\end{array}$ & $\mathrm{pH}$ & $\mathrm{P}$ & $\mathrm{K}^{+}$ & $\mathrm{Ca}^{++}$ & $\begin{array}{r}\mathrm{Mg}^{++} \\
\mathrm{cm}\end{array}$ & $\begin{array}{l}\mathrm{Na}^{+} \\
\mathrm{dm}^{3}\end{array}$ & $\mathrm{Al}^{+++}$ & S & CTC & $\mathrm{V}$ & $\%$ & $\mathrm{~m}$ \\
\hline $0-20 \mathrm{~cm}$ & 5,6 & 1,3 & 0,07 & 0,43 & 0,25 & 0,02 & 0,02 & 0,83 & 2,1 & 40,3 & & 03 \\
\hline $20-40 \mathrm{~cm}$ & 5,1 & 1,5 & 0,05 & 0,20 & 0,15 & 0,03 & 0,22 & 0,43 & 2,1 & 21,5 & & 31 \\
\hline
\end{tabular}


Tabela 2 - Análise física das amostras do solo da área experimental, São João-PE, nas profundidades 0 a 20 e de 20 a $40 \mathrm{~cm}$ Table 2 - Physical analysis of soils samples, at $0-20$ and $20-40 \mathrm{~cm}$ deep from experimental area, São João-PE

\begin{tabular}{|c|c|c|c|c|c|c|c|c|c|}
\hline \multirow[t]{2}{*}{$\begin{array}{l}\text { Camada } \\
\text { Stratum }\end{array}$} & \multicolumn{2}{|c|}{$\begin{array}{c}\text { Densidade }\left(\mathrm{g} / \mathrm{cm}^{3}\right) \\
\text { Density }\left(\mathrm{g} / \mathrm{cm}^{3}\right)\end{array}$} & \multicolumn{4}{|c|}{$\begin{array}{c}\text { Composição granulométrica (\%) } \\
\text { Granumelitry chemical (\%) }\end{array}$} & \multicolumn{2}{|c|}{$\begin{array}{l}\% \text { Argila } \\
\text { Clay (\%) }\end{array}$} & \multirow{2}{*}{$\begin{array}{c}\begin{array}{c}\text { Classe } \\
\text { Lay }\end{array} \\
\text { Text. } \\
\text { Texture }\end{array}$} \\
\hline & $\begin{array}{l}\text { Ap. } \\
\text { App. }\end{array}$ & $\begin{array}{l}\text { Real } \\
\text { Real }\end{array}$ & $\begin{array}{l}\mathrm{A} \mathrm{G} \\
C S\end{array}$ & $\begin{array}{l}\text { AF } \\
F S\end{array}$ & $\begin{array}{l}\text { Silte } \\
\text { Silt }\end{array}$ & $\begin{array}{l}\text { Argila } \\
\text { Clay }\end{array}$ & $\begin{array}{l}\text { Nat. } \\
\text { Nat. }\end{array}$ & $\begin{array}{l}\text { Floc. } \\
\text { Flak. }\end{array}$ & \\
\hline $0-20 \mathrm{~cm}$ & 1,52 & 2,70 & 81,83 & 9,83 & 6,00 & 2,33 & 0,00 & 100 & A \\
\hline $20-40 \mathrm{~cm}$ & 1,41 & 2,70 & 82,67 & 9,00 & 5,67 & 5,67 & 0,00 & 100 & A \\
\hline
\end{tabular}

Ap. (Aparente), AG (Areia grossa), AF (Areia fina), Nat. (Natural), Floc. (Floculada), Text. (Textura).

App. (Apparent), CS (Coarse sand), FS (Fine sand), Nat. (Natural), Flak. (Flake), Text. (Texture).

duas doses de adubo nitrogenado (0 e $100 \mathrm{~kg} / \mathrm{ha}$ de $\mathrm{N})$ e duas doses de adubo fosfatado $\left(0\right.$ e $100 \mathrm{~kg} / \mathrm{ha}$ de $\left.\mathrm{P}_{2} \mathrm{O}_{5}\right)$, totalizando 16 tratamentos, com três repetições.

As parcelas experimentais apresentavam área total de $40 \mathrm{~m}^{2}(10 \mathrm{~m} \times 4 \mathrm{~m})$ e área útil de $10,40 \mathrm{~m}^{2}(5,2 \mathrm{~m} \times 2 \mathrm{~m})$, com espaço entre parcelas de $2 \mathrm{~m}$ e entre blocos de $6,00 \mathrm{~m}$, totalizando $4.608 \mathrm{~m}^{2}$ de área experimental.

A gradagem foi realizada a aproximadamente $20 \mathrm{~cm}$ de profundidade, representando o método mecânico de preparo do solo, aplicado conforme o tratamento experimental.

A variedade de milho utilizada foi a Dentado Composto e o método de semeadura foi o manual, utilizando-se o espaçamento de $1 \times 0,4 \mathrm{~m}$, com profundidade de aproximadamente $3 \mathrm{~cm}$. Foram semeadas quatro sementes de milho/ cova, efetuando-se o desbaste aos 7 dias após da emergência das plântulas, deixando-se duas plântulas/cova, conferindo densidade de 50.000 plantas/ha. Na linha de semeadura do milho, foram aplicados quatro L/ha de herbicida préemergente (Gesaprim, cujo principal princípio ativo é o Atrazine). Nas áreas com plantio direto do milho, foram aplicados dois L/ha de herbicida pós-emergente (Gramoxone, cujo principal princípio ativo é o Paraquat) em toda área da parcela, para retardar o crescimento da Brachiaria decumbens e, desta forma, diminuir a competição inicial com as plântulas do milho.

Nos tratamentos com adubação, aplicou-se uréia como fonte de nitrogênio, parcelada em duas vezes, $50 \%$ por ocasião da semeadura e 50\% 30 dias após a primeira aplicação, diferente da adubação fosfatada, aplicada em uma única dose na semeadura, utilizando-se como fonte o superfosfato triplo.

Antes da aplicação dos tratamentos experimentais, visando apenas caracterizar a área, foram determinadas a disponibilidade de forragem, pelo método do rendimento comparativo (Haydock \& Shaw, 1975), e a composição botânica da pastagem, pelo método do peso seco escalonado, descrito por t' Mannetje \& Haydock e melhorada por Jones \& Hargreaves (1979). Para o processamento dos dados, foi empregado o programa computacional BOTANAL, desenvolvido por Hargreves \& Kerr (1978).

Em cada parcela experimental, foram traçados dois transectos paralelos distanciados aproximadamente $2 \mathrm{~m} \mathrm{um}$ do outro, no sentido longitudinal da parcela. Ao longo de cada transecto, em dez pontos delimitados por quadrados com $40 \mathrm{~cm}$ de lado, foram realizadas estimativas visuais e medição (com régua) da altura da pastagem, totalizando 20 quadrados-amostra por parcela.

As nove espécies de maior ocorrência na pastagem foram: capim-braquiária (Brachiaria decumbens Stapf.); lava prato (Waltheria indica L.; peludinho (Scrankia leptocarpa DC.); rama branca (Sida galheirensis Ulbr.); malva branca (Herissantia crispa (L.) Bris.); estilosantes (Stylosanthes scabra Vog); ervas e arbustos; outras leguminosas; malva preta (Pavonia cancellata (L.) Cav.), consideradas na determinação da disponibilidade de MS por componente botânico.

Após 138 dias da aplicação dos tratamentos (período de diferimento), no dia 05/10/2000, foram realizadas avaliações para determinação da produção de MS, da composição botânica, da altura de planta e da área de solo descoberto. Os dois últimos parâmetros foram obtidos de forma idêntica à primeira observação.

A produção de MS foi determinada pelo corte e pela pesagem de todo o material da área útil da parcela, multiplicado pelo teor de MS, obtido após a pré-secagem de parte deste material colhido em áreas delimitadas por três quadrados com $40 \mathrm{~cm}$ de lado, por meio do corte rente ao solo. Os quadradosamostra foram alocados em um transecto longitudinalmente ao comprimento da parcela a uma distância de 1,5 m um do outro. As amostras desta avaliação foram separadas manualmente em dois componentes botânicos principais, Brachiaria decumbens Stapf. e outras espécies.

Os dados foram avaliados por meio do programa estatístico Swntia (Embrapa, 1996) com análise de variância e desdobramento das interações quando significativas, aplicando-se o teste deDuncan a $5 \%$ de probabilidade para comparação de médias. 


\section{Resultados e Discussão}

$\mathrm{Na}$ área experimental, foram identificadas sete famílias, 16 gêneros e 16 espécies, com predominância de espécies da família Gramineae e presença de leguminosas como Estilosantes (Stylosanthes scabra Vog.), Camaecrista (Chamaecrista diphylla (L.) Greene) e alguns componentes arbustivos típicos da região do Agreste.

O estrato herbáceo da área estudada era formado, principalmente, pela gramínea exótica Brachiaria decumbens Stapf., com 79,9\% de participação e disponibilidade de $1.449,6 \mathrm{~kg} / \mathrm{ha}$ de MS (Tabela 3). A rama branca (Sida galheirensis Ulbr.) foi o componente com menor participação $(0,1 \%)$ na composição botânica da pastagem e, conseqüentemente, de menor disponibilidade $(3,0 \mathrm{~kg} / \mathrm{ha}$ de $\mathrm{MS})$.

A disponibilidade total de MS antes da aplicação dos tratamentos foi de $1.814 \mathrm{~kg} /$ ha de MS, a altura média do estrato de $6,3 \mathrm{~cm}$ e a área de solo descoberto de aproximadamente 40\%. Segundo Reis et al. (1997), a disponibilidade de MS inferior a $2.000 \mathrm{~kg} / \mathrm{ha}$ nos trópicos, independentemente da qualidade, reduz o consumo por animal.

Após a aplicação dos tratamentos, observou-se efeito significativo $(\mathrm{P}<0,05)$, pelo teste $\mathrm{F}$, dos métodos de recuperação e da interação nitrogênio $\times$ fósforo sobre a produção de MS.

Os métodos diferimento e diferimento + plantio direto apresentaram maior $(\mathrm{P}<0,05)$ acúmulo de $\mathrm{MS} /$ ha que os demais métodos utilizados, com produções de 5.545 e $4.226 \mathrm{~kg} / \mathrm{ha}$ de MS, respectivamente, não diferindo significativamente entre si. Os menores $(\mathrm{P}<0,05)$ acúmulos de MS foram obtidos nos tratamentos com gradagem, com $1.633 \mathrm{e}$ $1.708 \mathrm{~kg} / \mathrm{ha}$ de MS para diferimento + gradagem e diferimento + gradagem + milho, respectivamente, não evidenciando diferença significativa entre si (Tabela 4). Resultados semelhantes foram encontrados por Soares Filho et al. (1992), que constataram maior produção de MS em braquiária no tratamento sem preparo mecânico do solo. A gradagem também comprometeu a recuperação da $B$. humidicola em trabalho realizado no Agreste de Pernambuco e, em razão do baixo nível de fósforo do solo experimental, apenas a vedação associada à adubação fosfatada recuperou a pastagem (Silva et al., 2004).

Entretanto, Dias Filho (1998) relatou que a recuperação de pastagens degradadas pode ser tecnicamente viável quando utilizados conjuntamente métodos físicos e químicos. Costa (2000) afirmou que, em um solo Podzólico Vermelho-Amarelo distrófico, a adubação $(42 \mathrm{~kg} / \mathrm{ha}$ de $\mathrm{Ne}$ $44 \mathrm{~kg} / \mathrm{ha}$ de S) mostrou-se agronomicamente eficiente para a recuperação de pastagens de Brachiaria decumbens Stapf., enquanto o uso da grade, por si só, não proporcionou efeitos positivos.

O grande acúmulo de MS nos métodos com diferimento + plantio direto e diferimento pode ser atribuído à biomassa inicial de plantas, a qual foi pouco prejudicada por esses tratamentos quando comparada às áreas que receberam gradagem, possibilitando melhor e mais rápido aproveitamento dos fertilizantes aplicados.

A gradagem pode ter causado alto efeito negativo à forrageira pelo uso do implemento, não sendo observados os benefícios da mineralização da matéria orgânica e da adubação nitrogenada e fosfatada. Verificou-se também que a ressemeadura natural na pastagem submetida à gradagem proveio principalmente das sementes armazenadas no solo, demorando muito para que ocorresse a cobertura do solo, resultando, portanto, em maior aparecimento de outras ervas. Esse fato pode ser evidenciado pela produção de dois componentes principais, Brachiaria decumbens Stapf. e outras ervas (Figura 1). A disponibilidade

Tabela 3 - Composição botânica e disponibilidade de MS da pastagem antes da aplicação dos tratamentos, São João-PE

Table 3 - Botanical composition and availability of dry mather of the pasture in the experimental area before the treatment aplication, São João-PE

\begin{tabular}{|c|c|c|c|}
\hline $\begin{array}{l}\text { Componente } \\
\text { Component }\end{array}$ & $\begin{array}{l}\text { Nome vulgar } \\
\text { Common name }\end{array}$ & $\begin{array}{l}\text { Participação }(\%) \\
\text { Participation }(\%)\end{array}$ & $\begin{array}{c}\text { Disponibilidade }(\mathrm{kg} / \mathrm{ha} / \mathrm{MS}) \\
\text { Availability } \mathrm{kg} / \mathrm{DM} / \mathrm{ha}\end{array}$ \\
\hline Brachiaria decumbens & Braquiária & 79,9 & 1449,6 \\
\hline Waltheria indica $L$ & Lava prato & 7,3 & 132,3 \\
\hline Scrankia leptocarpa DC. & Peludinho & 6,6 & 119,7 \\
\hline Herissantia crispa (L.) Bris. & Malva branca & 1,2 & 19,9 \\
\hline Stylosanthes scabra Vog. & Estilosantes & 1,1 & 19,7 \\
\hline Pavonia cancellata (L.) Cav. & Malva preta & 0,6 & 11,1 \\
\hline Sida galheirensis Ulbr. & Rama branca & 0,1 & 3,0 \\
\hline Outras leguminosas & & 0,7 & 12,8 \\
\hline \multicolumn{4}{|l|}{ Other legumes } \\
\hline Ervas e arbustos & & 2,5 & 45,9 \\
\hline \multicolumn{4}{|l|}{ Herbs and shrubs } \\
\hline Total & & 100 & 1814 \\
\hline
\end{tabular}


Tabela 4 - Produção de MS total, solo descoberto e altura da pastagem nos diferentes manejos de recuperação após 138 dias de diferimento, São João-PE

Table 4 - Total dry matter yield, uncovered soil and pasture height, at different treatment recuperation at 138 days of rest, São João-PE

\begin{tabular}{|c|c|c|c|}
\hline $\begin{array}{l}\text { Tratamento } \\
\text { Treatment }\end{array}$ & $\begin{array}{l}\text { Produção de MS (kg/ha) } \\
\text { DM yield }\end{array}$ & $\begin{array}{l}\text { Solo descoberto (\%) } \\
\text { Uncovered soil }\end{array}$ & $\begin{array}{c}\text { Altura }(\%) \\
\text { Height }\end{array}$ \\
\hline $\begin{array}{l}\text { Diferimento } \\
\text { Control }\end{array}$ & $5545 \mathrm{a}$ & $1,8 \mathrm{~d}$ & $62,3 a$ \\
\hline $\begin{array}{l}\text { Dif. + gradagem } \\
\text { Control + plow }\end{array}$ & $1633 b$ & $85,4 a$ & $16,2 b$ \\
\hline $\begin{array}{l}\text { Dif. }+ \text { grad. }+ \text { milho* } \\
\text { Control }+ \text { plow }+ \text { corn }\end{array}$ & $1708 \mathrm{~b}$ & $76,3 \mathrm{a}$ & $12,4 b$ \\
\hline $\begin{array}{l}\text { Dif. + plant. dir. do milho* } \\
\text { Control }+ \text { no till plant of corn }\end{array}$ & $4226 a$ & $18,3 \mathrm{c}$ & $48,1 \mathrm{a}$ \\
\hline
\end{tabular}

Médias seguida de letra igual na coluna não diferem pelo teste Duncan a $5 \%$ de probabilidade.

Averages followed by the same letter in the column do not differ by Duncan test at $5 \%$ probability.

* Produção do milho é nula (Null yield corn).

de $5.545 \mathrm{~kg} /$ ha de MS obtida no método diferimento resultou do acúmulo da disponibilidade inicial $(1.814 \mathrm{~kg} / \mathrm{ha}$ de MS) mais a produção do período de diferimento (138 dias), ou seja, a produção real do método nesse período foi de $3.731 \mathrm{~kg} / \mathrm{ha}$ de MS. Por outro lado, a disponibilidade observada nos demais métodos representa a produção apenas no período de diferimento, em decorrência da grande redução e, até mesmo, da eliminação da biomassa vegetal inicial com o uso de grade ou herbicida.

A adubação nitrogenada na ausência de fósforo propiciou aumento de $34 \%$ na disponibilidade (de 2.110 para $2.817 \mathrm{~kg} /$ ha de matéria seca), porém, não diferiu da adubação com fósforo ( $\mathrm{P}>0,05)$, provavelmente em razão do alto coeficiente de variação $(\mathrm{CV}=59,4 \%)$ encontrado para esta variável (Figura 2).

Em experimento com Brachiaria brizantha cv. Marandu, Alexandrino (2000) testou a adição de diferentes doses de nitrogênio ao solo e observou aumento médio de $275 \%$ na

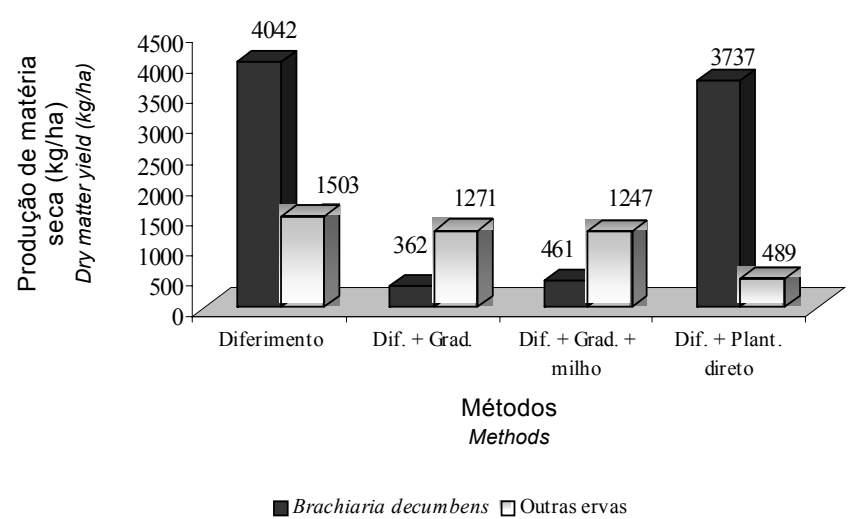

Figura 1 - Produção de MS por componente, aos 138 dias, São João-PE.

Figure 1 - Dry matter yield per component, at 138 days, São João-PE. produção de MS. Ruggieri et al. (1995), trabalhando com a mesma espécie, relataram que as plantas com diferimento acima de 56 dias revelaram tendência em acumular maiores quantidades de MS total.

A adubação fosfatada sem nitrogênio aumentou em $23 \%$ a disponibilidade de MS (de 2.110 para $2.595 \mathrm{~kg} / \mathrm{ha}$ ), não sendo observada diferença $(\mathrm{P}>0,05)$ entre os valores (Figura 2). Pereira (1986) afirma que inúmeros trabalhos comprovam que as espécies de braquiária não requerem aplicações de altas doses de fósforo no solo, pois são capazes de vegetar em solos com baixa disponibilidade desse nutriente, não requerendo mais de $45 \mathrm{~kg} / \mathrm{ha}$ de $\mathrm{P}_{2} \mathrm{O}_{5}$.

Houve interação significativa $(\mathrm{P}<0,05)$ para adição conjunta da adubação nitrogenada e fosfatada, propiciando aumento $(\mathrm{P}<0,05)$ na disponibilidade de forragem, que resultou em disponibilidade de $5.588 \mathrm{~kg} / \mathrm{ha}$ de MS quando a pastagem foi adubada com $100 \mathrm{~kg}$ de nitrogênio e de $\mathrm{P}_{2} \mathrm{O}_{5}$ simultaneamente. Assim, ambos os nutrientes proporcionaram

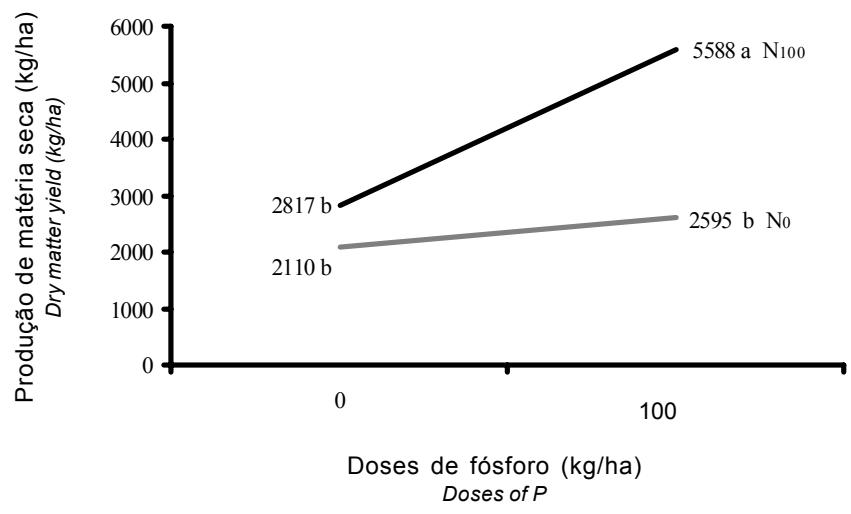

Figura 2 - Efeitos das doses de P e N sobre a produção de MS total de Brachiaria decumbens Stapf aos 138 dias de idade.

Figure 2 - Total dry matter production of Brachiaria decumbens Stapf, in function of doses of $P$ and $N$ at 138 days old. 
incremento $(\mathrm{P}<0,05)$ de $3.478 \mathrm{~kg} / \mathrm{ha}$ de MS, ou seja, $164,8 \%$ a mais em relação ao método diferimento (Figura 2). No tratamento diferimento, com a aplicação conjunta destes dois nutrientes, foi encontrada disponibilidade de MS de $9.343 \mathrm{~kg} / \mathrm{ha}$, ou seja, $3.755 \mathrm{~kg} / \mathrm{ha} / \mathrm{MS}(40,1 \%)$ a mais do que na média dos quatro sistemas. Resultados semelhantes foram obtidos por Costa et al. (2000), que observaram incrementos significativos na produção de MS de Brachiaria brizantha e $B$. decumbens com a aplicação de nitrogênio e fósforo.

A porcentagem de solo descoberto nos métodos com preparo mecânico do solo foi maior $(\mathrm{P}<0,05)$ que nos métodos diferimento e diferimento + plantio direto do milho. $\mathrm{O}$ diferimento proporcionou melhor cobertura, em torno de $98,2 \%$, ou seja, $58,2 \%$ a mais que no início do experimento (Tabela 4). Costa (2000) menciona que alta porcentagem de solo descoberto favorece o aumento da população de plantas invasoras, da erosão laminar e da profundidade pela ação direta das chuvas, pelas perdas por lixiviação da maior parte dos nutrientes disponíveis no solo, pela compactação e, finalmente, pela degradação, em alguns casos, quase irreversível.

Quanto à altura média da pastagem, os métodos diferimento e diferimento + plantio direto + milho foram superiores $(\mathrm{P}<0,05)$ aos demais e não diferiram entre si (Tabela 4). Todos os métodos encontram-se dentro dos limites mínimos estabelecidos $(10-20 \mathrm{~cm})$ para que ocorra maior facilidade na apreensão da forragem e melhor seleção da dieta pelos bovinos (Dubeux Jr. et al., 1997). O diferimento da parcela, por si só, promoveu aumento expressivo na altura da pastagem e diminuição da porcentagem de solo descoberto.

Aproximadamente 20 a 30 dias após germinação, as plântulas de milho sofreram ataque intenso de formigas saúvas (Atta ssp.). Em duas oportunidades, tentou-se realizar o controle físico e químico dos ninhos identificados nas proximidades, mas não se obteve sucesso, verificando-se a perda total da cultura em todos os tratamentos. As saúvas, do ponto de vista agrícola, são os insetos que mais causam danos à agricultura brasileira (Mariconi, 1970).

\section{Conclusões}

A gradagem não é uma prática agronômica viável para a recuperação de pastagens degradadas de Brachiaria decumbens Stapf. no Agreste Pernambucano.

O diferimento da pastagem por 138 dias no período chuvoso propicia sua recuperação, principalmente quando associado à adubação nitrogenada e fosfatada.
A recuperação de pastagem de Brachiaria decumbens Stapf. é expressivamente melhorada com a aplicação conjunta de adubos nitrogenado e fosfatado, por possibilitar a redução de outras espécies.

\section{Literatura Citada}

ARAÚJO FILHO, J.A.; ARAÚJO, S.M.C. Pastoreio combinado de bovinos, caprinos e ovinos em áreas de caatinga no Nordeste do Brasil. In: CONFERÊNCIA VIRTUAL GLOBAL SOBRE PRODUÇÃO ORGÂNICA DE BOVINOS DE CORTE, 1., 2002, Corumbá-MS. http://www.conferencia.uncnet.br

ALEXANDRINO, E.; NASCIMENTO JR., D.; MOSQUIM, P.R. et al. Características morfogênicas e estruturais na rebrotação da Brachiaria brizantha cv. Marandu submetida a três doses de nitrogênio. Revista Brasileira de Zootecnia, v.33, n.6, p.1372-1379, 2004

COSTA, N.L. Resposta de pastagens degradadas de Brachiaria brizantha cv. Marandu a doses de nitrogênio e fósforo. In: REUNIAO ANUAL DA SOCIEDADE BRASILEIRA DE ZOOTECNIA, 37., 2000, Viçosa, MG. Anais... Viçosa, MG: Sociedade Brasileira de Zootecnia, 2000. (CD-ROM)

DIAS FILHO, M.B. Pastagens cultivadas na Amazônia Oriental Brasileira: Processos e causas de degradação e estratégias de recuperação. In: DIAS, L.E.; MELLO, J.W.V. (Eds.) Recuperação de áreas degradadas. Viçosa, MG: Sociedade Brasileira de Recuperação de Áreas Degradadas, 1998. p.135-147.

DUBEUX JR., J.C.B.; LIRA, M.L.; FREITAS, E.V. et al. Avaliação de pastagens de braquiarias na Zona da Mata de Pernambuco. Revista Brasileira de Zootecnia, v.26, n.4, p.659-666, 1997. EMPRESA BRASILEIRA DE PESQUISA E AGROPECUÁRIA EMBRAPA - Centro nacional de pesquisa tecnológica em informática para a agricultura. SWNTIA, Versão 4.2.1. Instalação e programa. Campinas, 1996. v.3, Disquete.

FUNDAÇÃO DE INFORMAÇÕES PARA DESENVOLVIMENTO DE PERNAMBUCO. Informações municipais. São João, Recife, 1982, "não paginado".

HADDAD, C.M.; ALVES, F.V. Alimentos orgânicos para a suplementação de bovinos. In: CONFERÊNCIA VIRTUAL GLOBAL SOBRE PRODUÇÃO ORGÂNICA DE BOVINOS DE CORTE, 1., 2002, Corumbá. http://www.conferencia.uncnet.br

HAYDOCK, K.P.; SHAW, N.H. The comparative yield method of estimating dry matter yield of pasture. Australian Journal of Experimental Agriculture and Animal Husbandry, v.15, n.76, p.663-670, 1975 .

HARGREAVES, J.N.G.; KEER, J.D. BOTANAL - A comprehensive sampling and computing procedure for estimating pasture yield and composition. II. Computational package. In: - Tropical agronomy technical memoradum. 9. St. Lúcia, CSIRO Division of tropical crops and pastures, 1978. 88p.

HARGREAVES, G.H. Precipitation dependability and potentials for agricultural production in northeast Brasil. Logan: Utah State University, 1974.

JONES, R.M.; HARGREAVES, J.N.G. Improvements to the dryweight-rank method of measuring botanical composition. Grass Forage Science, v.34, n.2, p.181-189, 1979.

MACEDO, M.C.M. Degradação de pastagens; conceitos e métodos de recuperação In: SUSTENTABILIDADE DA PECUÁRIA DE LEITE NO BRASIL, 1999, Juiz de Fora. Anais... Juiz de Fora: 1999. p.137-150.

MARICONI, F.A. As saúvas. São Paulo: Agronômica Ceres, 1970 $167 \mathrm{p}$.

PEREIRA, J.P. Adubação de capins do gênero Brachiaria. In: ENCONTRO PARA DISCUSSÃO DOS CAPINS DO GÊNERO Brachiaria, 1986, Nova Odessa. Anais... Nova Odessa: Instituto de Zootecnia, 1986 
REIS, R.A.; RODRIGUES, L.R.A.; PEREIRA, J.R.A. Suplementação como estratégia de manejo de pastagem. In: REUNIAO ANUAL DA SOCIEDADE BRASILEIRA DE ZOOTECNIA, 34., 1997, Juiz de Fora. Anais... Juiz de Fora: Sociedade Brasileira de Zootecnia, 1997. p.249-251.

ROCHA, G.L. Situação das pastagens no Estado de São Paulo. In: PEDREIRA, J.V.S. (Ed.). Curso de manejo de pastagens. Nova Odessa: Instituto de Zootecnia, 1985. p.1-24.

RUGGIERI, A.C.; FAVORETTO, V.; MALHEIROS, E.B. Efeito de níveis de nitrogênio e regimes de corte na distribuição, na composição bromatológica e na digestibilidade in vitro da matéria seca da Brachiaria brizantha Stapf. Cv. Marandu. Revista Brasileira de Zootecnia, v.24, n.1, p.20-30, 1995.

SÁ, I.B.; RICHÉ, G.R.; FOTIUS, G.A. As paisagens e o processo de degradação do semi-árido nordestino In: MMA-UFPE (Ed.) Biodiversidade da caatinga: áreas e ações prioritárias para a conservação. Brasília: MMA-UFPE, 2004. p.17-36.
SILVA, M.C.; SANTOS, M.V.F.; DUBEUX JR., J.C.B. et al. Avaliação de métodos para recuperação de pastagens de braquiária no agreste de Pernambuco. 1. Aspectos quantitativos. Revista Brasileira de Zootecnia, v.33, n.6, p.1999-2006, 2004 (supl. 2).

SOARES FILHO, C.V.; MONTEIRO, F. A.; CORSI, M. Recuperação de pastagens degradadas de Brachiaria decumbens. 1. Efeito de diferentes tratamentos de fertilização e manejo. Pasturas Tropicales, v.14, n.2, p.2-6, 1992.

Recebido: 20/10/04 Aprovado:31/10/05 